\title{
Intercultural Relations Among Guinean Immigrants Living in Portugal: Testing Multiculturalism, Contact, and Integration Hypotheses
}

\author{
Félix Neto ${ }^{1}$ \\ University of Porto, Portugal
}

\begin{abstract}
This study tests several specific predictions derived from three general core hypotheses of intercultural relations (multiculturalism, contact, and integration hypotheses). The participants were 405 migrants from Guinea-Bissau (51 percent women). Their average age was 38 years. The average length of stay in Portugal was 18 years. Data collection involved the completion of questionnaires to measure multicultural ideology, security, cultural identity, contact, perceived discrimination, acculturation strategies, mental health problems, sociocultural adaptation, and tolerance. In concert with the multiculturalism hypothesis, security and cultural identity positively predicted multicultural ideology. The contact hypothesis was partially confirmed given that intercultural contact did not predict perceived discrimination, although contact predicted national identity. Regarding the integration hypothesis, integration strategy predicted psychological and intercultural adaptations, while the predictors of sociocultural adaptation were assimilation and marginalization. Hence, the integration hypothesis obtained partial support for migrants from Guinea-Bissau residing in Portugal. Finally, some implications of the findings are discussed. This study contributes to extending the integration hypothesis to a recently suggested new form of adaptation, intercultural adaptation. Feelings of being secure in the larger society and one's identity contributes to higher acceptance of diversity.
\end{abstract}

Keywords: acculturation, contact, integration, intercultural relations, multicultural ideology.

In this paper, we will examine several particular expectations grounded on three core general hypotheses of intercultural relations: multiculturalism, contact, and integration hypotheses among Guinean immigrants residing in Portugal. These three general hypotheses were derived from a framework for conceptualizing intercultural relations and acculturation in plural societies (Berry, 2017).

The multiculturalism hypothesis proposes that when people experience security in their group's and personal place in society concerning their cultural identity and their economic situation, they will be more accepting of those who differ from themselves (Berry et al., 1977). In other words, higher cultural confidence and security will conduct to greater intercultural acceptance. This acceptance encompasses embracing cultural diversity and intercultural contact, being tolerant, the reduction of discrimination, welcoming ethnocultural groups in the society (Berry, 2013). Conversely, if one's cultural identity or security are threatened, rejection of those who are different will occur.

Evidence for the multiculturalism hypothesis has been supported in several cultural contexts (Berry, 2017; Inguglia et al., 2020; Vedder et al., 2017). For example, in Canada,

\footnotetext{
${ }^{1}$ Corresponding Author E-Mail: fneto@fpce.up.pt
} 
multicultural ideology and feelings of security lead to higher acceptance of the immigrants (Berry et al., 1977). In New Zealand, security appeared linked to multicultural ideology and favorable opinions about migrants, whereas high threat predicted negative attitudes toward them (Ward \& Masgoret, 2008). In Portugal, support for the multiculturalism hypothesis was found among native youths: when they experienced security in their culturally plural society, they exhibited more tolerance towards migrants (Neto, 2009b). In Greece, Pavlopoulos and Motti-Stefanidi (2017) found that people who felt secure about their own identity and place in society showed higher acceptance of diversity. However, in Holland, the multiculturalism hypothesis was only partially supported, as a secure cultural identity was not related to a more accepting attitude toward out-groups (Verkuyten, 2018). In sum, some empirical support for the multiculturalism hypothesis has been shown, but further evidence is needed engaging other ethnocultural groups.

In what concerns the contact hypothesis it is proposed that intercultural contacts and sharing can stimulate mutual acceptance. This relationship was supported in several contexts, generally under certain conditions (e.g., equal status of groups in a situation, cooperation rather than competition, common goals, and support of authorities) (Allport, 1954). A metanalytic study has shown general support for this hypothesis (Pettigrew \& Tropp, 2006): intergroup contact related negatively to prejudice in both native and immigrant populations. More recent work has also supported the contact hypothesis, showing that positive intercultural contact was negatively related to prejudice and positively to multicultural ideology (e.g., Paluck et al., 2019; Titzmann et al., 2015; Vedder et al., 2017; Zhou et al., 2019). In sum, there is empirical support for the contact hypothesis, but further evidence is needed in particular concerning the relationship between social contacts and national identity in non-dominant group members.

The integration hypothesis is related to the framework of acculturation strategies, that is, how immigrants seek to relate in the larger society. According to Berry's (2017) acculturation framework, there are four acculturation strategies: integration, assimilation, separation, and marginalization. Integration presupposes migrants maintain their home culture and interact with other groups. Assimilation presupposes migrants do not wish to maintain their home culture and seek interactions with other cultures in the larger society. Separation occurs when individuals maintain their home culture and do not seek interactions with other cultures in the larger society. Finally, marginalization presupposes little possibility or interest in the maintenance of the home culture and little interest in interactions with others. Based on these concepts, the integration hypothesis argues that when members of non-dominant groups are "double engaged" with their heritage culture and host culture, they will display better levels of adaptation.

Evidence for the integration hypothesis has been supported in several cultural contexts (Abu-Rayya \& Sam, 2017; Berry et al., 2006; Inguglia et al., 2020; Motti-Stefanidi, 2018; Neto, 2002; Nguyen \& Benet-Martínez, 2013). In Canada and France, second generation immigrants reported that integration was associated with better adaptation and marginalization with poorer adaptation (Berry \& Sabatier, 2010). In Portugal, the integration strategy appeared positively related to psychological adaptation and sociocultural adaptation among young immigrants from Angola, Cape Verde, Guinea-Bissau, India, Mozambique, São-Tomé and East Timor (Neto, 2010). A meta-analysis found that integration ("biculturalism" in their terms) was positively related to both psychological adaptation (e.g., life satisfaction, positive affect, self-esteem) and sociocultural adaptation (e.g., academic achievement, career success, social skills, lack of behavioral problems) (Nguyen \& Bennet-Martinez, 2013).

However, some research has shown that integration is not always linked to the most beneficial acculturation outcome (Brown \& Zagefka, 2011; Gurer, 2019; Schotte et al., 2018; Ward, 2013). For example, Schotte et al. (2018) found that the adaptive potential of integration is limited in assimilative cultural settings, such as in Germany where identification with the mainstream culture but not with the ethnic context was related to better adaptation of 
immigrants. A mixed portrait of the relationships between integration orientation and sociocultural adaptation was found in Portugal. On the one hand, integration was positively related to sociocultural adaptation among immigrant youths (Neto, 2010), however, this relationship was not found among adult Cape Verdean (Neto, 2020) and Ukrainian (Neto, 2019) immigrants. Thereby, it is important to test the integration hypothesis in different ethnocultural groups that are understudied, such as the Guineans.

In sum, even if we can find in the published literature empirical support for these three general hypotheses (multiculturalism, contact, and integration), further evidence is needed involving other cultural settings and ethnocultural groups. To this end, we test several specific predictions derived from these three general hypotheses among Guinean migrants in Portugal.

\section{Guineans Living in Portugal}

This study intends to provide insight into three key principles of intercultural relations among Guinean migrants residing in Portugal. Guinea-Bissau is part of the Portuguesespeaking nations (PALOP) and is located in Africa with a population of over 1.5 million people. It is one of the world's poorest countries. The Human Development Index (HDI) from the United Nations Development Program places Guinea-Bissau at 164th place, out of 169 countries and territories (CountryWatch, 2020). Another important aspect of this country is its diversity. "Particularly in terms of ethnic differentiation, it comprises a remarkable variety of languages, cultural practices, and forms of social organization" (Abranches, 2014, p. 263).

Emigration from Guinea-Bissau "has been shaped by political turmoil, economic poverty, and non-state organizations' actions" (Pires, 2013, p. 155). In the context of departure from Guinea-Bissau, migration to Portugal has had two phases (Machado, 2002). The first occurred through the early 1960s and 1970s due to economic and political motivations. It especially concerned Portuguese nationals of Guinea-Bissau origin. The second phase occurred in the 1980s and 1990s, primarily due to poverty. It concerned Guinean nationals in particular. Pires (2013) points out that the paramount differences between these two groups are socioeconomic: "those with a Portuguese nationality have a higher income, a higher education, and social status than those who arrived later on" (pp. 155-156).

The number of legal Guinean immigrants to Portugal from the mid-1980s to the end of the 1990s increased from around 2,500 individuals to 12,500 in 1996.

In 2018, according to the Foreigners and Borders Service (Serviço de Estrangeiros e Fronteiras [SEF], 2019), the Guinean community consisted of 16,186 registered citizens, being the tenth immigrant community in this nation. They corresponded to $3.4 \%$ of the foreign population in Portugal. Gender distribution was relatively balanced in 2018, with 52,7\% men and $47,3 \%$ women. There was a greater proportion of Guinean immigrants aged between 20 and $49(62,9 \%)$ than among Portuguese $(37,6 \%)$, the majority of which were located in the Lisbon metropolitan area.

\section{The Present Study}

The current study has three objectives in connection with the three basic psychological principles of intercultural relations described earlier: multiculturalism, contact, and integration. The first objective is to analyze the multiculturalism hypothesis considering the relationships of multicultural ideology with security, and cultural identity. The endorsement of multiculturalism has been approached utilizing diverse conceptualizations (Berry, 2013). In this research we use a general construct of multiculturalism, that is, multicultural ideology (MCI) which refers to the general support of cultural diversity and equality in society (Berry, 2017). According to Tip et al. (2012), it is important to investigate predictors of support for 
multiculturalism given that multiculturalism can lead to more positive intergroup relations. Therefore, in this study it will be examined whether security and cultural identity predict multiculturalism.

Security has three components: cultural security, economic security, and personal security (Berry et al., 1977). Cultural security concerns the sense that elements of one's culture have a secure status in the society of settlement. Economic security concerns the sense that one's economic status does not diminish in the society of settlement. Personal security concerns the sense that people feel free to move around without being accosted or attacked. In this study, global security encompassing these three kinds of security will be considered. It is expected that when members of non-dominant groups feel secure, they exhibit high levels of multicultural ideology (Berry, 2017). In short, security will lead to greater acceptance of diversity.

Cultural identity refers to the immigrants' sense of self, covering both ethnic and national identities. The majority of investigations on migration have only examined ethnic identity (Shuangyun \& Hongxia, 2020); notwithstanding that, both identities are important for migrant peoples (Beckett \& Kobayashi, 2020; Coulmas, 2019; Fleischmann \& Verkuyten, 2016; Phinney, 2003). Substantial ethnic identity affords psychosocial strength and security for migrants (Phinney, 2003; Tran \& Bifuth-Ambe, 2021). Findings from Canadian surveys support the association of confidence in one's identity with mutual acceptance (Berry et al., 1977). This acceptance entails more positive views of multiculturalism.

The second objective is to test the contact hypothesis, examining the relations between social contact with native Portuguese, perceived discrimination, and Portuguese identity. Perceived discrimination concerns the subjective interpretation of being unfairly treated as a result of prejudice. It is a potentially serious acculturative stressor (Lee \& Ahn, 2011; Neto et al., 2019; Smith \& Khawaga, 2011; Suh et al., 2019). For example, Berry and Hou (2017) evidenced that perceived discrimination was significantly and negatively related to satisfaction with life and mental health of immigrants.

The contact hypothesis can also be linked to the identity of the host culture. Frequent and satisfactory social contacts of immigrants with native people can be related to a set of positive attitudes towards the host culture. In this case, immigrants may experience higher identification with people of the larger society and appreciation of other cultures. Therefore, we expect that contact would be related to prejudice reduction and acceptance of identification with the host culture (Inguglia et al., 2020; Pettigrew, 2008).

The third objective consists of testing the integration hypothesis by analyzing the relations of acculturation orientations with adaptation. Adaptation refers to outcomes of the process of acculturation, ranging from "well-adapted" to "mal-adapted" (Berry et al., 2006). For migrants, acculturation outcomes generally involve psychological, sociocultural, and intercultural adaptations. Psychological adaptation concerns "how comfortable and happy a person feels for being in a new culture or feeling anxious and out of place" (Demes \& Geeraert 2014 , p. 91). It is sometimes referred to as "feeling well". Mental health problems will be our indicator of psychological adaptation. There is literature that recognizes depression, anxiety, and psychosomatic symptoms as the most usual signs of mental health problems from acculturation outcomes (Berry et al., 2006; Neto, 2009a).

Sociocultural adaptation refers to "intercultural competence with emphasis on behavioral domains" (Ward \& Kennedy, 1999, p. 662). It is sometimes referred to as "doing well" in daily intercultural activities. Intercultural adaptation has been reported in more recent times as a third kind of adaptation (Berry, 2015). It concerns how well individuals can form harmonious intercultural relations. It can be termed "relating well" (Neto, 2019). Tolerance will be considered indicator of intercultural adaptation. This can be defined as an attitude toward social equality which includes both elements: ethnic tolerance and social egalitarianism (Berry, 2017). Therefore, in this investigation, we will consider the relationships of these three 
adaptation factors with the integration hypothesis, and based on previous research we expect that integration will positively predict the three adaptation factors among Guinean immigrants.

In sum, in light of the preceding literature review, the following seven specific hypotheses were formulated:

Multiculturalism hypothesis: Security and cultural identity positively predict acceptance of diversity. Specifically:

- H1a: Security would positively predict multicultural ideology.

- H1b: Cultural identity would positively predict multicultural ideology.

Specifically:

Contact hypothesis: Intergroup contact positively predicts intercultural acceptance.

- $\mathrm{H} 2 a$ : Contact with native Portuguese would negatively predict perceived discrimination.

- $\mathrm{H} 2_{b}$ : Social contacts with Portuguese would positively predict identification with Portuguese culture.

Integration hypothesis: Integration strategy positively predicts adaptation outcomes. Specifically:

- $\mathrm{H} 3$ a Integration strategy would positively predict psychological adaptation.

- H3b Integration strategy would positively predict sociocultural adaptation.

- $\mathrm{H} 3 \mathrm{c}$ Integration strategy would positively predict intercultural adaptation.

\section{Method}

\section{Sample}

Table 1

Socio-demographic characteristics of the Guinean immigrants

\begin{tabular}{ll}
\hline Mean age (SD) & Guineans $(\mathrm{N}=405)$ \\
Gender & $38.27(10.46)$ \\
Male & $217(53.6 \%)$ \\
Female & $184(45.4 \%)$ \\
Not answered & $4(1.0 \%)$ \\
Mean years in Portugal (SD) & $17.57(8.22)$ \\
Marital status & \\
Married & $199(49.1 \%)$ \\
Not Married & $193(47.7 \%)$ \\
Not answered & $13(3.2 \%)$ \\
Level of education & \\
Less than secondary school & $245(60.5 \%)$ \\
Secondary school & $71(17.5 \%)$ \\
Tertiary education & $55(13.6 \%)$ \\
Not answered & $34(8.4 \%)$ \\
Work & \\
Unskilled work & $155(38.3 \%)$ \\
Skilled work & $143(35.3 \%)$ \\
White collar work & $23(5.7 \%)$ \\
Professional work & $17(4.2 \%)$ \\
Without work & $59(14.6 \%)$ \\
Not answered & $8(2.0 \%)$ \\
Religion & \\
No religion & $60(14.8 \%)$ \\
Roman Catholic & $219(54.1 \%)$ \\
Protestant & $32(7.9 \%)$ \\
Muslim & $71(17,5 \%)$ \\
Other & $13(3.2 \%)$ \\
Not answered & $10(2.5 \%)$ \\
\hline
\end{tabular}


The sample consisted of 405 Guinean adults ( $45 \%$ females; $M_{\text {age }}=38.27, S D=10.46$, ages 18-65), who live in Portugal. The average length of stay in Portugal was 18 years $(S D=$ 8.22). Forty-nine percent of the sample was married. Regarding occupation, the modal category was unskilled employment (38\%). Concerning education, $60 \%$ had not completed secondary education, $18 \%$ had completed secondary education, and $14 \%$ had attended tertiary education. Regarding religious affiliation, 54\% reported to be Roman Catholic and 18\% Muslim (see Table $1)$.

\section{Instruments}

Acculturation strategies. A 20-item scale measured four acculturation strategies: integration, assimilation, separation, and marginalization (Berry et al., 1989; Neto, 2002). The statements cover five life domains: cultural traditions, languages, social activities, friends, and music. Each domain was assessed with four items. The Cronbach's alphas for integration, assimilation, separation, and marginalization in this sample were $.76, .85, .74$, and .84 , respectively.

Feelings of Security. A 13-item scale evaluated cultural, economic, and personal security (Berry, 2006). Sample statements are: "I am concerned about losing my cultural identity" (cultural; reverse-scored), "The high level of unemployment presents a grave cause for concern" (economic; reverse-scored), and "People's chances of being robbed, assaulted, and even murdered are getting higher and higher" (personal; reverse-scored). Options responses ranged from 1 ("totally disagree") to 5 ("totally agree"). In this investigation, Cronbach's $\alpha$ was .77.

Cultural identity. Cultural identity was evaluated with an instrument originally designed by Phinney (1992) (Neto \& Wilks, 2017). This measure evaluated Guinean identity with 4 statements (e.g., "I feel that I am part of Guinean culture") $(\alpha=.89)$. The other measure (4 statements) evaluated Portuguese identity (e.g., "I am happy that I am Portuguese") $(\alpha=.93)$.

Multicultural ideology. A 10-item scale measured respondents' acceptance of the perspective that cultural diversity is good for society (Berry \& Kalin, 1995; Neto, 2009b). Items (e.g., "We should recognize that cultural and racial diversity is a fundamental characteristic of Portuguese society") were evaluated with answer options from 1 ("totally disagree") to 5 ("totally agree"). We measured Cronbach's $\alpha$ as .75.

Perceived discrimination. This scale measures the perceived feeling of being treated unfairly because of one's ethnicity including 5 statements (Berry et al., 2006; Neto, 2006). Example items are: "I think that others have behaved unfairly or negatively towards my ethnic group" or "I don't feel accepted by Portuguese". Response ranged from 1 ("strongly disagree") to 5 ("strongly agree"). In this investigation, Cronbach's alpha $(\alpha)$ was .91.

Intercultural contact. To evaluate migrant's intercultural contact with native Portuguese the respondents indicated the number of close friends and frequency of contact with them (e.g., "How often do you meet with Portuguese people?") (Berry et al., 2006; Neto \& Fonseca, 2016) $(\alpha=.75)$.

Mental health problems. This measure was designed to evaluate depression, anxiety, and psychosomatic symptoms and consisted of 15 items (Berry et al., 2006; Neto, 2009a). 5 items were evaluating each of these three disorders. Example items are "I feel tired"; "I feel tense and anxious" and "I feel lonely even if I am with people" corresponding to psychosomatic symptoms, anxiety, and depression, respectively. Response ranged from 1 ("not at all") to 5 ("very often"). Cronbach's $\alpha$ was measured as .91.

Sociocultural Adaptation. This measure assesses competence in daily intercultural interactions of migrants (Ward \& Kennedy, 1999; Sequeira Neto, 2014). The scale includes 20 areas of daily life (e.g., "The pace of life" and "Going to social gatherings"). Response ranged 
from 1 ("no difficulty") to 5 ("extreme difficulty"). Items were recoded positively. In this investigation, Cronbach's $\alpha$ was .93.

Tolerance. An 11-item scale measured both one's ethnic tolerance (six items; e.g., "It is good to have people from different ethnic and racial groups living in the same country") and social egalitarianism (five items; e.g., "We should promote equality among all groups, regardless of racial or ethnic origin") (see Berry, 2006; Neto, 2009a). Response ranged from 1 ("totally disagree") to 5 ("totally agree"). In this investigation, Cronbach's $(\alpha)$ was .72.

Demographics. Additionally, participants indicated their age, gender, place of birth, age at arrival in Portugal, education level, and work.

\section{Procedure}

The survey was administered by a trained research assistant accompanied by a Guinean collaborator in the Lisbon metropolitan area. The participants were recruited in shops, associations, and communities. Additionally, immigrants were recruited by means of the snowball method (family members or migrants' friends). Regarding ethical considerations, the research was performed in agreement with the legal and ethical norms of the country. Respondents were acquainted with the aims of the investigation and provided informed consent. Respondents were free to withdraw from the research at any time without consequence. Completing the survey generally took less than $30 \mathrm{~min}$. All respondents were unpaid volunteers.

\section{Data Analyses}

The data were analyzed using descriptive statistics, internal consistencies analysis of variance, Pearson's correlations, and multiple regressions. To demonstrate the factors affecting multicultural ideology, intercultural contact, and adaptation, hierarchical regression models were performed. The statistical analyses were conducted by means of the IBM SPSS Statistics version 26.

\section{Results}

Descriptive statistics, internal consistency coefficients, and Pearson's correlations for the Guinean immigrants are shown in Table 2.

\section{Table 2}

Means, standard deviations, and reliability coefficients of the measures for the Guinean immigrants

\begin{tabular}{lcccc}
\hline & $M$ & $S D$ & $\begin{array}{c}\text { Number } \\
\text { of items }\end{array}$ & Cronbach's $\alpha$ \\
\hline Integration & 3.60 & .87 & 5 & .76 \\
Assimilation & 2.57 & .96 & 5 & .85 \\
Separation & 2.60 & .88 & 5 & .74 \\
Marginalization & 2.26 & .94 & 5 & .84 \\
Security & 3.34 & .67 & 15 & .77 \\
Ethnic identity & 4.14 & .99 & 4 & .89 \\
National identity & 2.92 & 1.32 & 4 & .93 \\
Multicultural ideology & 3.32 & .72 & 10 & .75 \\
Perceived discrimination & 2.36 & 1.11 & 5 & .91 \\
Intercultural contacts with Portuguese & 3.56 & .96 & 2 & .75 \\
Mental health problems & 2.89 & .83 & 15 & .91 \\
Sociocultural adaptation & 3.55 & .91 & 20 & .93 \\
Tolerance & 3.61 & .66 & 11 & .72 \\
\hline
\end{tabular}




\section{Multiculturalism Hypothesis}

To test the predictive power of overall security, we conducted hierarchical multiple regression. The effects of age and gender were controlled. In the first step, age and gender were entered. In the second step and last step, feeling secure was entered. The variance inflation factor was below 2 and the tolerance statistic exceeds .20, indicating no problems with multicollinearity (Field, 2017). This was done in all the following multiple regressions which were performed. As shown in Table 3, feelings of security significantly predicted multicultural ideology $(\beta=.69, p<.001)$, after controlling for the demographics. The direction of this effect was positive, in line with the multiculturalism hypothesis. In this sample, neither age nor gender significantly affected multicultural ideology $\left(p^{\prime} s>.05\right)$. The overall model explains an impressive amount of $48 \%$ of the variance in multicultural ideology. The results support $\mathrm{H} 1_{\mathrm{a}}$.

\section{Table 3}

Hierarchical regression models for overall security and other variables predicting multicultural ideology and tolerance

\begin{tabular}{lcc}
\hline & \multicolumn{2}{c}{ Multicultural ideology } \\
Variables & Block 1, $\beta$ & Block 2, $\beta$ \\
\hline Age & -.02 & -.01 \\
Gender & -.06 & -.01 \\
Overall security & & $.69 * * *$ \\
& & \\
$R^{2}$ & .00 & .48 \\
Adjusted $R^{2}$ & .00 & .48 \\
$F$ change & .82 & $334.93^{* * *}$ \\
\hline$* * p<.001$. & &
\end{tabular}

Next, we tested the predictive power of cultural identity. As shown in Table 4, identification with both groups, ethnic identity $(\beta=.20, p=.001)$ and national identity $(\beta=.36$, $p<.001)$ significantly predicted multicultural ideology after controlling for the demographic variables. The direction of this effect was positive, in line with the multiculturalism hypothesis. In this sample, neither age nor gender significantly affected multicultural ideology $\left(p^{\prime} s>.05\right)$. The overall model explains $12 \%$ of the variance in multicultural ideology. The results support $\mathrm{H} 1_{\mathrm{b}}$.

\section{Table 4}

Hierarchical regression models for cultural identity and other variables predicting multicultural ideology

\begin{tabular}{lcc}
\hline & \multicolumn{2}{c}{ Multicultural ideology } \\
Variables & Block $1, \beta$ & Block $2, \beta$ \\
\hline Age & -.01 & -.01 \\
Gender & -.05 & -.02 \\
Ethnic identity & & $.20^{* * *}$ \\
National identity & & $.36^{* * *}$ \\
$R^{2}$ & & .12 \\
Adjusted $R^{2}$ & .01 & .11 \\
$F$ change & .01 & $23.19^{* * *}$ \\
\hline$* * p<.001$. & .39 &
\end{tabular}




\section{Contact Hypothesis}

To test the influence of contact with Portuguese to predict perceived discrimination (i.e., lack of perceived acceptance), we employed multiple hierarchical regression models. We entered demographics again in the first step and contact with Portuguese in the second step. Contact with Portuguese, $\beta=.01, p=.78$, did not predict perceived discrimination, after controlling for age and gender. Neither age nor gender was significant. Therefore, our $\mathrm{H} 2 \mathrm{a}$ was not supported.

Next, we tested the influence of contact with the Portuguese to predict national identity. Contact with Portuguese $(\beta=.22, p=<.001)$ did predict Portuguese identity, after controlling for age and gender. Neither age nor gender was significant. This model explained 5 percent of the total Portuguese identity. Therefore, our $\mathrm{H} 2 \mathrm{~b}$ was supported.

\section{Table 5}

Hierarchical regression models for contacts with Portuguese and other variables predicting Portuguese identity

\begin{tabular}{lcc}
\hline & \multicolumn{2}{c}{ Portuguese identity } \\
Variables & Block 1, $\beta$ & Block 2, $\beta$ \\
\hline Age & -.05 & -.04 \\
Gender & -.05 & -.07 \\
Contacts with Portuguese & & $.22 * * *$ \\
& & \\
$R^{2}$ & .01 & .05 \\
Adjusted $R^{2}$ & .01 & .04 \\
$F$ change & .88 & $18.01 * * *$ \\
$* * * p<.001$. & &
\end{tabular}

\section{Integration Hypothesis}

Correlation findings showed that integration was negatively associated with mental health problems $(r=-.24, p<.001)$, and positively associated with tolerance $(r=.27, p<.001)$. However, integration was not significantly associated with sociocultural adaptation $(r=-.03, p$ $>$.05). These results provide initial partial support for hypothesis 3 .

\section{Table 6}

Correlations between intercultural strategies of Guinean immigrants and adaptation outcomes

\begin{tabular}{lccc}
\hline & $\begin{array}{c}\text { Psychological } \\
\text { adaptation }\end{array}$ & $\begin{array}{c}\text { Sociocultural } \\
\text { adaptation }\end{array}$ & $\begin{array}{c}\text { Intercultural } \\
\text { adaptation }\end{array}$ \\
\hline Integration & $-.24 * * *$ & -.03 & $.27 * * *$ \\
Assimilation & $.28 * * *$ & $-.38^{* * *}$ & $-.51 * * *$ \\
Separation & $.20^{* * *}$ & $-.29 * * *$ & $-.35 * * *$ \\
Marginalization & $.37 * * *$ & $-.38^{* * *}$ & $-.58 * * *$ \\
\hline$* * * p<.001$. & & &
\end{tabular}

We used multiple regressions analysis again and tested the integration hypothesis. Specifically, we tested whether an integration orientation predicted mental health problems, sociocultural adaptation, and tolerance. We entered age and gender again in the first step and acculturation strategies in the second step. As shown in Table 7, integration significantly 
predicted mental health problems $\beta=-.19, p=.001$, and tolerance, $\beta=.23, p=.001$, respectively, after controlling for the demographics. The predictors explained 18 percent and 39 percent of the total variance in mental health problems and tolerance, respectively. These findings supported hypotheses $3 \mathrm{a}$ and $3 \mathrm{c}$. However, integration did not significantly predict sociocultural adaptation, $\beta=.05, p>.05$, after controlling for age and gender, indicating that younger participants and lower assimilation and marginalization had higher sociocultural competence. This result did not support hypothesis $3 \mathrm{~b}$.

Table 7

Hierarchical regression models for acculturation strategies and other variables predicting adaptation outcomes

\begin{tabular}{|c|c|c|c|c|c|c|}
\hline \multirow[b]{2}{*}{ Variables } & \multicolumn{2}{|c|}{$\begin{array}{l}\text { Psychological } \\
\text { adaptation }\end{array}$} & \multicolumn{2}{|c|}{$\begin{array}{c}\text { Sociocultural } \\
\text { adaptation }\end{array}$} & \multicolumn{2}{|c|}{$\begin{array}{c}\text { Intercultural } \\
\text { adaptation }\end{array}$} \\
\hline & $\begin{array}{c}\text { Block 1, } \\
\beta\end{array}$ & Block $2, \beta$ & $\begin{array}{c}\text { Block 1, } \\
\beta\end{array}$ & $\begin{array}{c}\text { Block 2, } \\
\beta\end{array}$ & $\begin{array}{c}\text { Block 1, } \\
\beta\end{array}$ & $\begin{array}{c}\text { Block 2, } \\
\beta\end{array}$ \\
\hline Age & .08 & .07 & $-.17 * *$ & $-.14 * *$ & -.03 & -.01 \\
\hline Gender & .07 & .04 & .06 & .07 & .05 & $.10^{*}$ \\
\hline Integration & & $-.19 * * *$ & & -.05 & & $.23 * * *$ \\
\hline Assimilation & & .06 & & $-.20^{* *}$ & & $-.25^{* * * *}$ \\
\hline Separation & & .04 & & -.08 & & -.09 \\
\hline Marginalization & & $.27 * * *$ & & $-.18 *$ & & $-.31 * * *$ \\
\hline$R^{2}$ & .01 & .18 & .03 & .20 & .01 & .39 \\
\hline Adjusted $R^{2}$ & .01 & .17 & .02 & .19 & -.01 & .38 \\
\hline$F$ change & 2.04 & $17.78 * * *$ & $5.04 * *$ & $17.66 * * *$ & .66 & $58.31 * * *$ \\
\hline
\end{tabular}

\section{Discussion}

This study investigated basic psychological aspects of the intercultural relations from an understudied ethnocultural group (Guinean) of adults residing in Portugal. We made specific expectations grounded on three general hypotheses: multiculturalism, contact, and integration. These hypotheses were generated from investigation about intercultural relations in Canada and internationally. Results of the current study are partially consonant with the hypotheses.

The multiculturalism hypothesis received support in this study. The multiculturalism hypothesis predicts that security will be associated with more acceptance of people from different cultures and ethnocultural groups. Current study showed that overall security positively predicted multicultural ideology. This finding highlights the importance of the perception of being secure for immigrants (Hui et al., 2015; Hanke et al., 2017; Inguglia et al., 2017).

The multiculturalism hypothesis also predicts that confidence in one's cultural identity will be associated with more acceptance of diversity. Current findings showed that ethnic identity as well as national identity positively predicted multicultural ideology. In sum, a high sense of being secure in the larger society and one's cultural identity contributed to greater intercultural acceptance, including greater multicultural ideology scores. It may be possible to presume that multiculturalism may be good for intercultural relations in Portugal. Sam et al. (2017, p. 143) have observed that "studies examining the multiculturalism hypothesis to date are not as extensive as those that have examined the other two hypotheses". Hence, the current study's support for this hypothesis adds a positive contribution to understanding it.

The contact hypothesis suggests that intercultural contact will enhance mutual acceptance. The two expectations derived from the contact hypothesis were mixed. On one 
hand, in line with our predictions $(\mathrm{H} 2 \mathrm{~b})$, contact with people of the larger society did predict Portuguese identity. In other words, migrants identify more with the people of the society of settlement when they engage in contact with them.

On the other hand, inter-group contact did not predict low levels of perceived discrimination. This is not consonant with some past research (e.g., Titzmann et al., 2015; Vedder et al., 2017). Nevertheless, the contact hypothesis received only partial support in other studies (e. g., Hanke et al., 2017; Sam et al., 2017). One possible explanation may be that many of the conditions (e.g., common goals; intergroup cooperation; and support of authorities) suggested by Allport (1954) for the contact hypothesis were not controlled. Another possible explanation may be that the measure of intercultural contact used in this study was not the best. Perhaps a more valid measure of intercultural contact might have supported the hypothesis.

The integration hypothesis suggests that when immigrants seek integration by being "double engaged" in both their home culture and host culture, they have more positive adaptation outcomes. Consistent with results from various international studies (e.g., AbuRayya \& Sam, 2017; Berry \& Hou,2017; Inguglia et al., 2020; Motti-Stefanidi, 2018; Nguyen \& Benet-Martínez, 2013), integration is the most preferred strategy among Guineans in Portugal. Most of this sample prefers to be doubly engaged - in Portuguese society and their heritage culture. These individuals are not very different from other immigrant groups in Portugal in their preferred acculturation strategies (Neto, 2002; 2019). The reason for this preference may be that "individuals and groups come to realize that this is the most psychologically satisfying way of living in culturally plural societies" (Berry \& Hou, 2017, p. 37). Previous research has shown that the preferred acculturation expectation of people from the society of settlement was multiculturalism (Neto \& Neto, 2017). Thus, both groups seem to prefer integration/multiculturalism as the most preferred strategy. These acculturations are consensual, and thus are likely to enhance social harmony (Bourhis et al., 1997).

As expected, the relationship between integration acculturation strategy and psychological adaptation was supported, as integration negatively predicted mental health problems (H3a). This result supports the benefits of integration for psychological adaptation (Berry et al., 2006; Ward \& Geeraert, 2016) and is consonant with a meta-analysis showing a link between integration orientation and psychological acculturation outcome (Nguyen \& Benet-Martinez, 2013).

However, although integration did not predict sociocultural adaptation $(\mathrm{H} 3 \mathrm{~b}$ ), assimilation and marginalization did predict it. Identical findings have been observed in this country among Cape Verdean and Ukrainian immigrants (Neto, 2019; 2020). This finding may have a connection with the duration of the sojourn. The average length of stay for this sample was 18 years. There is research pointing to a positive relationship of integration orientation with sociocultural adaptation in a short-term period of residence, but no longer (Jasinskaja-Lahti et al., 2011). Along the same lines, Wilson et al. (2013) have observed that "sociocultural adaptation difficulties are greatest on arrival in a new culture and decrease predictably over time" (p. 901).

As expected, the relationship between integration and intercultural adaptation was supported, as integration positively predicted tolerance $(\mathrm{H} 3 \mathrm{c})$. Hence, this finding contributes to extending the integration hypothesis to a recently suggested new form of adaptation, intercultural adaptation.

The findings of this study should be viewed considering some limitations. First, given that this work does not have a representative sample or longitudinal data, the generalizability of the results is limited, and causal claims cannot be made. Second, the measures were all selfreport, and consequently, they might reflect social desirability bias. In addition, the models tested in the present study evidenced a low to moderate explained variance, indicating that other relevant variables intervene in the intercultural relations. Despite the aforementioned 
limitations, the findings are in line with a novel contribution to international research examining simultaneously three research hypotheses (multiculturalism, contact, and integration). Current work suggests some support for the universality of the three core principles of intercultural relations "of providing a secure and nondiscriminatory social and cultural environment, of opportunities for equitable intercultural contact and participation, and of ways to be engaged in and identify with more than one culture" (Berry, 2020, p. 13). They provide insights for changing in direction to more harmonious plural societies.

This study also provides important practical implications. For instance, as the integration is linked to psychological adaptation and intercultural adaptation of immigrants it is important to promote this acculturation strategy. Intervention programs should be designed for immigrants in order to provide them facilities to maintain their home culture and to promote their participation in the host society. Intervention programs should also try to increase the feelings of security for Guineans in the society of settlement. In addition, the promotion of contact with the native people may help immigrants to identify with the host culture.

A positive relationship of security with the acceptance of others was found in this study with immigrants. A similar finding emerged among native people (Neto \& Neto, 2017). This mutual agreement suggest that it is possible to promote "a common strategy for enhancing the feelings of security among all groups” (Berry, 2017, p. 380).

\section{References}

Abranches, M. (2014). Remitting wealth, reciprocating health? The "travel" of the land from Guinea-Bissau to Portugal. American Ethnologist, 41, 261-275. http://dx.doi.org/10.1111/amet.12074

Abu-Rayya, H. M., \& Sam, D. L. (2017). Is integration the best way to acculturate? A reexamination of the bicultural-adaptation relationship in the "ICSEY" data set using the bilineal method. Journal of Cross-Cultural Psychology, 48, 287-293. http://dx.doi.org/10.1177/0022022116685846.

Allport, G. W. (1954). The nature of prejudice. Addison-Wesley.

Beckett, G. H., \& Kobayashi, M. (2020). A Meta-study of an Ethnographic Research in a Multicultural and Multilingual Community: Negotiations, Resources, and Dilemmas. American Journal of Qualitative Research, 4(1), 85-106. https://doi.org/10.29333/ajqr/8267

Berry, J. W. (2006). Mutual attitudes among immigrants and ethnocultural groups in Canada. International Journal of Intercultural Relations, 30, 719-734. http://dx.doi.org/10.1016/j.ijintrel.2006.06.004

Berry, J. W. (2013). Research on multiculturalism in Canada. International Journal of Intercultural Relations, 37, 663-675. http://dx.doi.org/10.1016/j.ijintrel.2013.09.005

Berry, J. W. (2015, June). Intercultural adaptation to acculturation [Paper presentation]. Annual Conference, Canadian Psychological Association Annual Conference, Ottawa, Canada.

Berry, J. W. (2017). Mutual intercultural relations in plural societies. Cambridge University Press. http://dx.doi.org/10.1017/9781316875032.010

Berry, J. W. (2020). How shall we all live together? In S. Safdar, C. Kwantes, \& W. Friedlmeier (Eds.), Wiser world with multiculturalism: Proceedings from the 24th Congress of the International Association for Cross-Cultural Psychology. https://scholarworks.gvsu.edu/iaccp_papers/284

Berry, J. W., \& Hou, F. (2017). Acculturation, discrimination and wellbeing among second generation of immigrants in Canada. International Journal of Intercultural Relations, 61, 29-39. http://dx.doi.org/10.1016/j.ijintrel.2017.08.003 
Berry, J. W., \& Kalin, R. (1995). Multicultural and ethnic attitudes in Canada: An overview of the 1991 national survey. Canadian Journal of Behavioral \& Science, 27, 301-320. https://doi.org/10.1037/0008-\%20400X.27.3.301

Berry, J. W., \& Sabatier, C. (2010). Acculturation, discrimination, and adaptation among second generation immigrant youth in Montreal and Paris. International Journal of Intercultural Relations, $34, \quad 191-207$. http://dx.doi.org/10.1016\%20/\%20j.i\%20jintrel.\%202009.11.007

Berry, J. W., Kalin, R., \& Taylor, D. (1977). Multiculturalism and ethnic attitudes in Canada. Supply \& Services.

Berry, J. W., Kim, U., Power, S., Young, M., \& Bujaki, M. (1989). Acculturation attitudes in plural societies. Applied Psychology: An International Review, 38, 185-206. http://dx.doi.org/10.1111/j.1464-0597.1989.tb01208.x.

Berry, J. W., Phinney, J. S., Sam, D. L. \& Vedder, P. (Eds.). (2006). Immigrant youth in cultural transition: Acculturation, identity, and adaptation across national contexts. Lawrence Erlbaum Associates.

Bourhis, R., Moise, C., Perrault, S., \& Senecal, S. (1997). Towards an interactive acculturation model: A social psychological approach. International Journal of Psychology, 32, 369386. http://dx.doi.org/10.1080/002075997400629

Brown, R., \& Zagefka, H. (2011). The dynamics of acculturation: An intergroup perspective. In J. M. Olson \& M. P. Zanna (Eds.), Advances in experimental social psychology (Vol. 44, pp. 129-184). Academic Press.

Coulmas, F. (2019). Identity: A very short introduction. Oxford University Press. http://dx.doi.org/10.1093/actrade/9780198828549.001.0001

CountryWatch. (2020). Guinea-Bissau country review. CountryWatch, Inc.

Demes, K. A., \& Geeraert, N. (2014). Measures matter: Scales for adaptation, cultural distance, and acculturation revisited. Journal of Cross-Cultural Psychology, 45, 91-109. http://dx.doi.org/10.1177/0022022113487590

Field, A. (2017). Discovering statistics using IBM SPSS statistics (5th ed.). SAGE.

Fleischmann, F., \& Verkuyten, M. (2016). Dual identity among immigrants: Comparing different conceptualizations, their measurements, and implications. Cultural Diversity and Ethnic Minority Psychology, 22(2), 151. http://dx.doi.org/10.1037/cdp0000058

Gurer, C. (2019). Refugee Perspectives on Integration in Germany. American Journal of Qualitative Research, 3(2), 52-70. https://doi.org/10.29333/ajqr/6433

Hanke, K., Egmont, M., Rohmann, A., \& Boehnke, K. (2017). Intercultural relations in Germany. In J. W. Berry (Ed.), Mutual intercultural relations (pp. 145-166). Cambridge University Press. http://dx.doi.org/10.1017/9781316875032.010.

Hui, B. P. H., Chen, C. X., Leung, C. M., \& Berry, J. W. (2015). Facilitating adaptation and intercultural contact: The role of bicultural integration and multicultural ideology in dominant and non-dominant groups. International Journal of Intercultural Relations, 45, 70-84. http://dx.doi.org/10.1016/j.ijintrel.2015.01.002.

Inguglia, C., Musso, P., \& Lo Coco, A. (2017). Intercultural relations in Italy. In J. W. Berry (Ed.), Mutual intercultural relations (pp. 210-230). Cambridge University Press. http://dx.doi.org/10.1017/9781316875032.010.

Inguglia, C., Musso, P., Albiero, P., Cassibba, R., Iannello, N. M., Lo Cricchio, M, G., Liga, F., Berry, J. W., \& Lo Coco, A. (2020). Mutual intercultural relations among immigrant and autochthonous youth in Italy: Testing the integration, multiculturalism, and contact $\begin{array}{lllll}\text { hypotheses. } & \text { Ricerche } & \text { Psicologia, } & 1, & 45-79 .\end{array}$ http://dx.doi.org/\%2010.3280/RIP2020001004 
Jasinskaja-Lahati, I., Horencjyk, G., \& Kimunen, T. (2011). Time and context in the relationship between acculturation attitudes and adaptation among Russia-speaking immigrants in Finland and Israel. Journal of Ethnic \& Migration Studies, 37, 1423-1440.

Lee, D. L., \& Ahn, S. (2011). Discrimination against Latina/os: A meta-analysis of individuallevel resources and outcomes. The Counseling Psychologist, 40, 28-65. http://dx.doi.org/10.1177/0011000011403326

Machado, L. F. (2002). Contrastes e continuidades, migracão, etnicidade e integracão dos guineenses em Portugal [Contrasts and continuities, migration, ethnicity and integration of Guineans in Portugal]. Celta Editora.

Motti-Stefanidi, F. (2018). Resilience among immigrant youth: The role of culture, development and acculturation. Developmental Review, 50, 99-109. http://dx.doi.org/10.1016/j.dr.2018.04.002

Neto, F. (2002). Acculturation strategies among adolescents from immigrant families in Portugal. International Journal of Intercultural Relations, 26, 17-38. http://dx.doi.org/10.1016/S0147-1767(01)00036-0

Neto, F. (2006). Psycho-social predictors of perceived discrimination among adolescents of immigrant background: A Portuguese study. Journal of Ethnic \& Migration Studies, 32, 89-109. http://dx.doi.org/10.1080/13691830500335507

Neto, F. (2009a). Predictors of mental health among adolescents from immigrant families in Portugal. Journal of Family Psychology, 23, 375-385. http://dx.doi.org/10.1037/a0015831

Neto, F. (2009b). Are attitudes of young Portuguese towards immigration also hardening? A comparison between 1999 and 2006. In A. Gari \& K. Mylonas (Eds.), Quod erat demonstrandum: From Herodotus' ethnographioc journeys to cross-cultural research (pp. 255- 264). Pedio Books Publishing.

Neto, F. (2010). Portugal intercultural: Aculturação e adaptação de jovens de origem imigrante [Intercultural Portugal: Acculturation and adaptation of young people of immigrant origin]. Livpsic.

Neto, F. (2019). Intercultural relations among Ukrainian immigrants living in Portugal. Universitas Psychologica, 18, 1-11. https://doi.org/10.11144/Javeriana.upsy18-5.irau

Neto, F. (2020). Intercultural relations among Cape Verdean immigrants living in Portugal. Journal of International Migration \& Integration, 21, 765-780. https://doi.org/10.1007/s12134-019-00679-8

Neto, F., \& Fonseca, A. C. (2016). The satisfaction with migration life scale. International $\begin{array}{lllll}\text { Journal of } & \text { Intercultural }\end{array}$ http://dx.doi.org/10.1016/j.ijintrel.2016.07.004

Neto, F., \& Neto, J. (2017). Intercultural relations in Portugal. In J. W. Berry (Ed.), Mutual intercultural relations (pp. 249-266). Cambridge University Press. http://dx.doi.org/10.1017/9781316875032.012

Neto, F., \& Wilks, D. (2017). Predictors of psychological adaptation of Cape Verdean students in Portugal. Journal of College Student Development, 58, 1087-1100. http://dx.doi.org/10.1353/csd.2017.0085

Neto, F., Pinto, M. C., \& Mullet, E. (2019). Can music reduce national prejudice? A test of a cross-cultural musical education programme. Psychology of Music, 47(5), 747-756. http://dx.doi.org/10.1177/0305735618774867

Nguyen, A. M., \& Benet-Martinez, V. (2013). Biculturalism and adjustment: A meta-analysis. $\begin{array}{lllll}\text { Journal of Cross-Cultural Psychology, } & 44, & 122-159 .\end{array}$ http://dx.doi.org/10.1177/0305735618774867http://dx.doi.org/10.1177/0022022111435 097

Paluck, E., L., Green, S., Green, D. (2019). The contact hypothesis re-evaluated. Behavioural Public Policy, 3, 129-158. http://dx.doi.org/10.1017/bpp.2018.25 
Pavlopoulos, V., \& Motti-Stefanidi, F. (2017). Intercultural relations in Greece. In J. W. Berry (Ed.), Mutual intercultural relations (pp. 187-209). Cambridge University Press. http://dx.doi.org/10.1017/9781316875032.009

Pettigrew, T. F. (2008). Future directions for intergroup contact theory and research. International Journal of Intercultural Relations, 32, 187-199. http://dx.doi.org/10.1016/j.ijintrel.2007.12.002

Pettigrew, T. F., \& Tropp, L. R. (2006). A meta-analytic test of intergroup contact theory. Journal of Personality \& Social Psychology, 90, 751-783. http://dx.doi.org/10.1037/0022-3514.90.5.751

Phinney, J. (1992). The multigroup ethnic identity measure: A new scale for use with diverse groups. Journal of Adolescent Research, 7, 156-176.

Phinney, J. (2003). Ethnic identity and acculturation. In K. M. Chun, P. B. Organista, \& G. Marín (Eds.), Acculturation: Advances in theory, measurement, and applied research (pp. 63-81). American Psychological Association.

Pires, S. (2013). Guinea-Bissau immigrant transnationalism in Portugal: A substitute for a failed state? African and Black Diaspora: An International Journal, 6, 145-173, http://dx.doi.org/10.1080/17528631.2013.793135

Sam, D. L., Veitk, R., Makarova, M., \& Raudsepp, M. (2017). Intercultural relations in Norway. In J. W. Berry (Ed.), Mutual intercultural relations in plural societies (pp. 125-144). Cambridge University Press. http://dx.doi.org/10.1017/9781316875032.006

Schotte, K., Stanat, P., \& Edele, A. (2018). Is integration always most adaptive? The role of cultural identity in academic achievement and in psychological adaptation of immigrant students in Germany. Journal of Youth \& Adolescence, 47, 16-37. http://dx.doi.org/10.1007/s10964-017-0737-

Sequeira Neto, J. (2014). Cultural competence among Ukrainian economic immigrants living in Portugal [Unpublished master's thesis]. Universidade do Porto.

Serviço de Estrangeiros e Fronteiras. (2019). Relatório de imigração, fronteira e asilo 2018 [Immigration, Border and Asylum Report 2018]. SEF.

Shuangyun, Y., \& Hongxia, L. (2020). Knowledge mapping of ethnic identity and acculturation based on the method of bibliometric. Journal of Ethnic \& Cultural Studies, 7, 17-33. http://dx.doi.org/10.29333/ejecs/370

Smith, R., \& Khawaja, N. (2011). A review of the acculturation experiences of international students. International Journal of Intercultural Relations, 35, 699-713. http://dx.doi.org/10.1016/j.ijintrel.2011.08.004

Suh, H. N., Flores, L. Y., \& Wang, K. T. (2019). Perceived discrimination, ethnic identity, and mental distress among Asian international students in Korea. Journal of Cross-Cultural Psychology, 50, 991-1007. http://dx.doi.org/10.1177/0022022119874433

Tip, L., Zagefka, H., González, R., Brown, R., Cinniralla, M., \& Na, X. (2012). Is support for multiculturalism threatened by ... threat itself? International Journal of Intercultural Relations, 36, 22-30. http://dx.doi.org/10.1016/j.ijintrel.2010.09.011

Titzmann, P. F., Brenick, A., \& Silbereisen, R. K. (2015). Friendships fighting prejudice: A longitudinal perspective on adolescents' cross-group friendships with immigrants. Journal of Youth \& Adolescence, 44, 1318-1331. http://dx.doi.org/ 10.1007/s10964-0150256-6.

Tran, T., \& Bifuh-Ambe, E. (2021). Ethnic identity and second-generation Vietnamese American adolescents. Journal of Ethnic \& Cultural Studies, 8, 167-186.

Vedder, P., Wenink, E., \& van Geel, M. (2017). Intergroup contact and prejudice between Dutch majority and Muslim minority youth in the Netherlands. Cultural Diversity \& Ethnic Minority Psychology, 23, 477-485. http://dx.doi.org/ 10.1037/cdp0000150. 
Verkuyten, M. (2018). The social psychology of ethnic identity (2nd ed.). Psychology Press. http://dx.doi.org/10.4324/9781315109527-2

Ward, C. (2013). Probing identity, integration and adaptation: Big questions, little answers. International Journal of Intercultural Relations, 37, 391-404. http://dx.doi.org/10.1016/j.ijintrel.2013.04.001

Ward, C., \& Geeraert, N. (2016). Advancing acculturation theory and research: The acculturation process in its ecological context. Current Opinion in Psychology, 8, 98104. http://dx.doi.org/10.1016/j.copsyc.2015.09.021

Ward, C., \& Kennedy, A. (1999). The measurement of sociocultural adaptation. International Journal of Intercultural Relations, 23, 659-677. http://dx.doi.org/10.1016/S01471767(99)00014-0

Ward, C., \& Masgoret, A. M. (2008). Attitudes toward immigrants, immigration, and multiculturalism in New Zealand: A social psychological analysis. International Migration Review, 42, 227-248. http://dx.doi.org/10.1111/j.17477379.2007.00119.

Wilson, J., Ward, C., \& Fisher, R. (2013). Beyond culture learning theory: What can personality tell us about cultural competence? Journal of Cross-Cultural Psychology, 44, 900-927. http://dx.doi.org/10.1177/0022022113492889

Zhou, S., Page-Gould, E., Aron, A., Moyer, A., \& Hewstone, M. (2019). The extended contact hypothesis: A meta-analysis on 20 years of research. Personality \& Social Psychology Review, 23, 132-160. http://dx.doi.org/10.1177/1088868318762647

\section{Notes on Contributor}

Félix Neto is a Full Professor Emeritus of Psychology in the Department of Psychology at the University of Porto, Portugal. His research interests include social psychology and crosscultural psychology (especially, migration, mental health, love, loneliness, and forgiveness). 